\title{
CONSUMO SUSTENTÁVEL \& ECONOMIA SOLIDÁRIA: ALGUNS CONCEITOS E CONTRIBUiÇÕES DA PSiCOlOGIA
}

Lilia Aparecida Kanan ${ }^{\star}$

\begin{abstract}
Resumo
O artigo sistematiza brevemente os consumos alienante, solidário e sustentável e dá visibilidade à proposta renovadora das relações econômicas estabelecidas na sociedade, representada pelos empreendimentos da economia solidária. Por meio do entendimento de alguns autores e pesquisadores verifica-se que as contribuições da Psicologia dadas ao tema assentam-se na problematização das práticas de consumo e suas significativas diferenças entre classes sociais, no questionamento dos novos modelos de economia e de organizações de trabalho sob a ótica das relações que entre eles se processam e na emergência de intervenções que contribuam para tornar autônomos os sujeitos que protagonizam essas novas propostas.
\end{abstract}

Palavras-chave: consumo sustentável; economia solidária; consumo e Psicologia.

\section{SUSTAINABLE CONSUMPTION \& SOLIDARY ECONOMY: SOME CONCEPTS AND CONTRIBUTIONS OF PSYCHOLOGY}

\begin{abstract}
The article explores briefly the alienating, sustainable and solidarity consumption and give visibility to the proposed renewal of economic relations established in society, represented by the solidarity economy enterprises. Through the understanding of some authors and researchers verified that the contributions of psychology to the issue made based on the inquiry of consumption practices and their significant differences between social classes, the questioning of new models of economy and labor organizations in the perspective of the relations that take place between them and the emergence of interventions that help to make autonomous subjects who play these new proposals.
\end{abstract}

Keywords: sustainable consumption; solidary economy; consumption and Psychology.

\footnotetext{
^Psicóloga. Doutora em Psicologia, docente e pesquisadora da Universidade do Planalto Catarinense. Endereço: Av. Castelo Branco, 170 - Bairro Universitário Caixa Postal 525 - Lages - Santa Catarina. CEP: 88509900.

E-mail:1ak@uniplac.net
} 
Ainda que exista no cenário mundial certa preocupação social com os problemas ambientais, eles continuam sendo vivenciados por um significativo número de pessoas em todos continentes. O êxodo rural, por exemplo, transferiu do campo para a cidade, mais precisamente para as periferias, um contingente populacional significativo que, em realidade, pouca atenção recebe dos poderes constituídos. $\mathrm{O}$ modelo hegemônico de sociedade baseado no consumo de grande escala, desenvolvimento tecnológico e exploração dos recursos naturais, cada vez mais intensamente, provoca marcantes desequilíbrios em micro e mega escala (PINHEIRO, 1997).

Em resposta a essas situações-problema, algumas ciências emprestam seus saberes à proposição de soluções, que possam (minimamente) promover "qualidade" em lugares ou cidades e bem-estar de pessoas inseridas nesses contextos. A Sociologia, a Economia, a Antropologia, mais recentemente, a Psicologia têm contribuições a oferecer no que tange à sustentabilidade, consumo, crescimento demográfico, miséria humana ou degradação dos sistemas naturais, por exemplo.

Historicamente, a Psicologia centrou pesquisas, pesquisadores, autores e articulistas em estudos acerca da influência do ambiente sobre as pessoas, relegando a um segundo plano possibilidades de compreensão e conhecimento sobre o influxo das pessoas no ambiente. Nas últimas décadas, questões de ordem política, ideológica, humanitária, entre outras, possibilitaram a concretização de uma Psicologia mais social e mais voltada ao coletivo do que ao individual, contrapondo-se a seu originário modelo médico. Subárea da Psicologia, a Psicologia Ambiental propõe-se a "analisar, explicar e fornecer informações capazes de identificar as condições envolvidas na congruência pessoa-ambiente e no bem-estar e, portanto, ajudar a tomada de decisões em questões ambientais" (MOSER, 2003. p. 331).

De maneira a contribuir com as reflexões propostas pela Psicologia Ambiental, ao se dar visibilidade aos conceitos-tema deste estudo, parte-se do entendimento que "todas as chamadas questões ambientais são na verdade questões 'humano'-ambientais [e estas, por sua vez, protagonizam] não uma crise 'ambiental', mas uma crise das 'pessoas-nos-ambientes'” (PINHEIRO, 1997, p. 377).

\section{Psicologia, CONSUMo e CONSUMidor}

Um dos aspectos que estabelece relação entre Psicologia Ambiental, comportamento humano e sustentabilidade é o consumo. Essa relação é possível em razão de o ato de comprar não necessariamente estar vinculado apenas ao ato de adquirir bens para o consumo. Conforme Mance (1999), as pessoas buscam nas mercadorias mais do que suas qualidades objetivas. São conferidos aos produtos qualidades virtuais: desejos, anseios, medos, angústias e necessidades são modelizados de tal modo que consumir certos produtos passa a ser considerado como a melhor opção para alcançar a felicidade, a realização, a concretização dos desejos mais íntimos, a superação dos obstáculos, conquistar sucesso, reconhecimento, 
prestígio... Comprar pode representar, ainda, um comportamento em resposta a experiências de frustração, carência afetiva, solidão e rejeição. O consumo, de acordo com essas perspectivas, é denominado por Mance (1999) de alienante.

Destaca Santos (2006) que estudar a cultura de consumo é imergir no estudo da própria humanidade, que desde suas origens tem sido investigada por meio de seus hábitos alimentares, de vestimenta e de utensílios, o que representa ato de subsistência e em muito difere dos padrões de consumo, hoje em vigor. Para o autor, o que difere o homem coletor de eras remotas do homem contemporâneo é a mudança nos comportamentos de consumir que deixaram de ser utilitaristas ou subsistenciais, associados à satisfação das necessidades básicas, para se configurar em consumo de conceitos. Explica o autor que ocorre o consumo conceitual quando, para além de produtos, são consumidos conceitos ou a representação destes e quando os valores agregados aos produtos mostram-se mais necessários que os mesmos.

No estágio de evolução em que se encontra a humanidade, é pertinente considerar que o sentido final do consumo não é mais necessariamente o produto, ou aquilo que foi produzido, antes, sim, o que eles representam. Tais constatações evidenciam o entendimento de Gade (1998) sobre comportamento. Para esse autor, "o comportamento é uma manifestação externa de processos psicológicos internos, de respostas aos estímulos que são processados e transformados em informações aprendidas e memorizadas" (GADE, 1998, p. 27). Como o comportamento humano pressupõe relações, é imprescindível considerar sua dinamicidade e seus múltiplos direcionamentos. Isto posto, é compreensível o fato de o homem tanto interferir no ambiente que o circunscreve, quanto esse ambiente influenciar suas ações. A dimensão ética que marca essa relação integra o conceito de comportamento, uma vez que o direciona.

Assim, é possível compreender a complexidade do comportamento de compra ou consumo, uma vez que estão envolvidas as dimensões econômica, comportamental, cognitiva e emocional. Depreende-se que comprar é o aspecto observável no processo de consumir. É parte de um processo de decisão cujos antecedentes e consequentes sempre merecem exame (GADE, 1998).

Corrales (2005) destaca que o consumo é determinado basicamente por três perspectivas: a primeira retrata o consumo como determinado por necessidades objetivas, por meio das quais os bens são consumidos em razão da importância dessas necessidades e a quantidade de recursos disponíveis para satisfazê-las. Representam seus consumidores sujeitos individuais, livres e racionais, decididos a consumir de acordo com a lógica do tipo custo-benefício, o chamado homo-economicus weberiano.

A segunda perspectiva, segundo Corrales (2005), desenvolveu-se com a Psicologia, particularmente de correntes como a psicanálise. Esse enfoque abandona a ideia de sujeito racional para colocar ênfase nas dimensões inconscientes de necessidades e motivações situadas na base do consumo, ou seja, os objetos já não são reduzidos a seu valor de uso. Neles se reconhecem o valor da marca, uma 
certa capacidade de simbolização que lhes permite representar coisas encontradas para além de suas razões práticas e que rompem a relação consumo-necessidade para assumir a interação consumo-desejo.

A terceira perspectiva, intrinsecamente associada à anterior, é concebida pela intercessão entre a sociologia e a antropologia e pressupõe o consumo como uma forma simbólica de conservação e reprodução da sociedade. Sob este enfoque, o consumo não satisfaz apenas as necessidades materiais, como também representa a importante função cultural de legitimar e consolidar maneiras concretas de entender a vida diária no contexto de determinadas sociedades.

Nessa era de consumo, assim referida por Kincheloe (1997), no centro do estilo de vida pós-moderno, onde parece prevalecer a segunda perspectiva descrita por Corrales (2005), o próprio consumo e as empresas que constróem a cultura do consumo, produzem sentidos. Os sentidos, por sua vez, constroem identidades, produzem pessoas e discursos. Em razão de tornar as pessoas sujeitos de consumo, influenciadas por discursos que projetam imagens, estilos de vida, de viver e de ser, subjacem aos produtos imagens atreladas, como também os estilos que intrinsecamente carregam. Nestes termos, Steinberg (1997) considera que as pessoas são, em alguma medida, aquilo que consomem.

Santos (2006) destaca que a globalização, por ser um processo tanto social, quanto econômico, político e cultural, é um dos principais estimuladores da cultura de consumo. O autor justifica a afirmação pelo fato de a globalização favorecer a circulação de produtos, imagens e ideias em escala mundial, "transformando o mundo em uma espécie de supermercado global em que muitas vezes as culturas locais são solapadas acabando por uniformizar as subjetividades em torno do consumo" (SANTOS, 2006, p. 79).

Quando dissipadas, exauridas, desconsideradas as subjetividades, as formas de recreação, interação social, modos de pensar e agir se fazem mediados pelo consumo e a vida em sociedade transforma-se em produto.

As pessoas se reúnem em confrarias de fumadores de charuto, apreciadores de vinhos caros, conhecedores de música erudita, degustadores de pratos exóticos, colecionadores de arte, portadores de perfurações no corpo ou qualquer objeto ou idéia que agregue um valor socioeconômico ou símbolo de status aquele que o ostente, porém, são incapazes de se reunir em torno de um objetivo comum que não esteja ligado a valores pecuniários e objetos quantificáveis (SANTOS, 2006, p. 89).

Sob essa perspectiva há que se considerar o consumo como uma forma de aceitação e consentimento com a ordem estabelecida e com as relações de poder existentes na sociedade e, nesse sentido são merecedoras de destaque as palavras de Baudrillard (1995, p. 207) acerca da sociedade de consumo: 
Se a sociedade de consumo já não produz mitos é porque ela constitui o seu próprio mito. Em vez do diabo que trazia o ouro e a riqueza (pelo preço da alma) surgiu a Abundância pura e simples. Em vez do pacto com o Diabo, o contrato de Abundância. Por outro lado, assim como o aspecto mais diabólico do Diabo nunca foi existir, mas sugerir que existe - também a Abundância não existe, basta-lhe, porém, fazer crer que existe, para se transformar em mito eficaz.

A esse conjunto de reflexões podem ser acrescidas outras, por exemplo, é necessário considerar o comportamento do mercado e seus movimentos sobre os fatores que influenciam a decisão de consumo. É inevitável considerar, sob essa ótica, os fatores intrínsecos à cultura, hábitos, costumes; os aspectos sociais representados pelos líderes, inovadores e seguidores; os aspectos pessoais perpassados pela idade, sexo, posição social, estilo de vida e escolaridade; e os aspectos psicológicos determinados pela informação, captação e decodificação. Tais aspectos são utilizados com extrema sapiência pelo mercado cuja intrincada cadeia de interdependência inexoravelmente influencia o consumidor e o direciona ao consumo.

E o consumidor? Esse sujeito, por ser dotado de personalidade, determina maior atração a determinados tipos de produtos em detrimento de outros. É fato que para algumas pessoas, alguns produtos, objetos ou coisas são imprescindíveis, enquanto para outras eles são supérfluos ou desnecessários. No entendimento de Karsaklian (2000), o consumidor tem preferências que podem ser distintas em relação aos demais, em razão de primazias associadas a processos de identificação ou a produtos que parecem representar justamente o que se quer apresentar. Embora dotado de personalidade e preferências, o consumidor não pensa e nem age sozinho, uma vez que está inserido em uma rede de relações. E a partir da interpretação dessa realidade é que irá avaliar e realizar suas experiências de consumo (CHAUVEL, 1999).

Não raro, o consumidor é cerceado, abalroado, induzido pela lógica do consumo que o espreita como um consumidor permanente, que reduz sua autonomia, e que entrega os menos críticos à total passividade, conformismo e à incapacidade de decidir livremente. Esses, por raramente questionarem, satisfazem suas necessidades usufruindo os artigos ou produtos que são, em última instância, determinados por aquilo que Steinberg (1997) denomina de tecnopoder midiático. Analogamente, Baudrillard (1997) assevera que as pessoas passaram a valorizar sobremaneira as aparências e a viver a supremacia dos objetos. A efemeridade atribuída às coisas converge para que tudo desapareça e se exaure facilmente. No entanto, quem desaparece são os milhões de telespectadores que esperam ser arrancados da inexistência.

Chauvel (1999), estabelecendo um contraponto ao pressuposto de tal passividade, argumenta ser necessário compreender o conjunto de fatores associados ao fenômeno da satisfação/insatisfação presente no ato de consumir. Assim, para além de uma visão reducionista, a autora argumenta que expectativas, normas 
construídas ao longo da experiência, percepção de equidade, desejos e objetivos constituem critérios que retratam separadamente aspectos interventores na relação entre aquele que produz e aquele que consome.

A respeito de aspectos presentes no ato de consumir, de maneira semelhante à Chauvel (1999), Boone e Kurtz (2001) destacam que o consumidor e suas decisões recebem tanto influência externas (família, classe social, grupos de referência e cultura), quanto internas (fatores psicológicos como motivação, aprendizagem, percepção, atitude e autoconceito).

Resta claro, então, que o consumidor pode ser tanto alienado, quanto crítico; tanto passivo, quanto apresentar crítica ao decidir; tanto possuidor de real capacidade para priorizar, quanto vulnerável aos desejos. À tamanha heterogenia subjaz o entendimento a respeito do que é consumo e do que representa viver em coletivos. E sob este prisma o ato de criticar reveste-se de legitimidade.

Críticas ao consumismo e ao consumo alienante são manifestas em muitos espaços. Contudo, as forças do sistema capitalista ainda mantêm boa parte da sociedade refém de seus ditames. Essa mazela se torna evidente na indução de necessidades ou na criação de falsas-necessidades, nas formas amplamente facilitadas de pagamento, no acúmulo de itens não prioritários. Nesses termos, alguns extratos da sociedade tornam-se cada vez mais vulneráveis ao endividamento, fenômeno que carreia consigo consequências nefastas ao indivíduo e às famílias.

Padua (2000) faz referência ao fato de: (a) 1/5 da humanidade (cerca de 1, 2 bilhões de pessoas) representa o grupo de alto consumo, responsável por $81,2 \%$ do comércio mundial; este grupo consume $92 \%$ dos carros privados, $75 \%$ da energia, $80 \%$ do ferro e aço, $81 \%$ do papel, $85 \%$ dos produtos químicos e $86 \%$ do cobre e alumínio; (b) $3 / 5$ da humanidade (cerca de 3,6 bilhões de pessoas) respondem por $17,8 \%$ do comércio mundial e por $10 \mathrm{a} 15 \%$ do consumo energético e da produção industrial do planeta; (c) $1 / 5$ da população mais pobres do planeta (cerca de 1, 2 bilhões de pessoas) responde por 1\% do comércio mundial. Este grupo não consome ou pouco consome veículos, eletricidade, telefone, computadores, Internet, por exemplo.

Tais números destacam a significativa desigualdade em termos de acesso ao consumo entre as camadas da sociedade. E neste viés, é pertinente referir que, no Brasil, as políticas econômicas centralizam os incluídos no mercado de consumo, "para os quais se pensa e se executa a política macroeconômica. Assim, são descartados de imediato aproximadamente os $30 \%$ da população que só existem como clientes das políticas sociais do Estado e não contam para formulação das políticas macroeconômicas" (TOSCANO apud BARBOSA, 2005, p. 157). Ou seja, aqueles que pouco acesso têm ao consumo tendem a permanecer nesta condição dadas as formulações governamentais, político-econômicas.

É fato também que a sociedade de consumo, nos moldes em que está atualmente configurada, é insustentável. A rápida obsolescência de tudo o que é consumido pela sociedade, a abundância material a que está submetida em razão do consumo não consciente predizem insuportáveis consequências ao 
ambiente. Aumento permanente da extração de recursos naturais, despejo de resíduos na natureza sem tratamento adequado, esgotamento dos recursos de primeira ordem à sobrevivência humana, constante ameaça à capacidade de regeneração da natureza, aumento expressivo da quantidade de lixo tecnológico são alguns exemplos a serem citados.

Criticar o consumo desmedido e predatório às pessoas e ao ambiente remete à defesa de mudanças radicais nos modelos de desenvolvimento internalizados por significativa parcela da sociedade. Negar produtos fabricados via exploração do trabalhador e do ambiente, bem como promover alterações estruturais da sociedade e dos padrões de consumo, representam possíveis transformações deste status quo (PÁDUA, 2000; BARBOSA, 2005).

Assim, por meio da reflexão a respeito das características elencadas sobre o consumo, o mercado consumidor, o indivíduo e a sociedade que consome com vistas à qualidade de vida, é pertinente considerar o que Mance (1999) evidencia: cada ato de consumo é um gesto de dimensão planetária que pode tornar o consumidor um cúmplice de ações desumanas e ecologicamente prejudiciais, ou pode tornar o consumidor corresponsável pela geração de emprego, pela preservação de ecossistemas, pela reciclagem de materiais, pelo combate à poluição, por exemplo.

A sustentabilidade decorrente do consumo consciente e ético representa,assim, possibilidade de intervenção de psicólogos ambientais. Destaca Moser (2003) que, para a Psicologia Ambiental, a qualidade de vida, ainda que seja resultado da saudável relação indivíduo-ambiente, não é padronizável. Antes, sim, fruto das necessidades das pessoas em relação ao que elas entendem por bem-estar. Há que se considerar, então, as necessidades das pessoas e o que efetivamente elas consomem e que traduz o seu bem-estar. Para o autor, o ambiente exerce efeitos sobre as ações humanas, pois materializa as psicologias daqueles que vivem nele, atribui significados, promove identidades e localiza a pessoa nos contextos social, cultural e econômico.

\section{Trabalho, RelaÇões E CONSTITUiÇão do SUJEITo SOB A ÓTICA Da ECONOMIA SOLIDÁRIA}

No Brasil, ao longo dos últimos 30 anos, instauraram-se novas formas de convivência e novas tendências na sociedade. De acordo com Silva (2004), uma das mais importantes, em razão de sua extensão e consequências, foi a substituição do preceito "luta de classe" por "movimento social". O autor observa que tal mudança paradigmática representou profundas alterações dos objetivos organizacionais, que passaram a valorizar e concretizar transformações importantes no cotidiano das pessoas em lugar de valorizar a tomada de poder revolucionariamente.

$\mathrm{Na}$ era contemporânea, as relações sociais e o subjacente caráter contraditório que as marcavam, criaram oportunidades para que distintos atores sociais protagonizassem a busca de oportunidades para o encaminhamento de suas demandas ou necessidades. Assim, os trabalhadores e outros atores sociais, por se perceberem privados ou distantes de chances de inclusão no mercado de trabalho 
e excluídos de oportunidades de consumir o que minimamente poderiam desejar para suprir o seu bem-estar começaram a pensar e agir sob uma perspectiva do interesse de muitos e do bem comum.

A exclusão econômica e o decorrente alijamento do consumo básico representou fator-chave para que a sociedade civil buscasse alternativas capazes de suprir ou minimamente atender às necessidades daqueles que estavam à margem das oportunidades. Unidades produtivas comunitárias de pequeno porte passaram a ser constituídas, favorecendo as soluções de emprego e renda, bem como contribuindo para satisfazer as demandas de consumo dos excluídos. Passou a se tornar visível, no Brasil, ainda que de maneira insipiente, uma nova sociedade baseada na colaboração solidária. Diante dessa conjuntura, o trabalho associativo e cooperativo configurou-se como resposta viável.

Mance (1999) descreve este novo modelo econômico - a economia solidária - como uma estratégia para um projeto alternativo de sociedade que cria um modelo próprio de organização do trabalho; constitui um microcosmo da economia global. Fundamenta-se na organização solidária da produção, em que todos trabalham e produzem e todos ganham. Baseia-se na organização coletiva em moldes democráticos, igualitários e está centrado na concessão mútua de avais solidários.

Destarte, foi o mercado consumidor um dos responsáveis por injustiças sociais e horrores econômicos, que, em associação aos princípios comunitários e coletivos, promoveu a economia solidária. Silva (2004) identifica como propositores da economia solidária os excluídos sociais, cuja motivação decorreu de suas experiências fornecidas pelas vicissitudes da vida, já que eram os que sentiam, de maneira contundente, o abandono, a falta de apoio e de condições indispensáveis à vida. Conforme o autor, os outros extratos sociais não se fizeram incluir nesta proposição, pois não sofriam as agruras e dificuldades para subsistir e, de certo modo, suas crises existenciais eram compensadas por meio da satisfação dos apelos do consumo alienante.

O trabalho é um espaço privilegiado de constituição do sujeito. É uma categoria central no desenvolvimento do autoconceito e uma fonte de autoestima (ZANELLI, 2007). Nesse espaço, coexistem relações e experiências que caracterizam e constituem a vida no sentido coletivo, a partir da singularidade de cada um dos sujeitos que dela fazem parte. Os defensores da economia solidária propõem que, por meio do trabalho sustentado por esse modelo, as pessoas podem construir identidades sociais, usufruir inserção e valorização pessoal, consumir de acordo com suas necessidades e reconhecerem-se como sujeitos de sua própria existência. Encontra-se em Oliveira (2004) que, neste modelo de economia, os indivíduos têm sua autoestima fortalecida e tal decorre do reconhecimento de suas próprias capacidades, da possibilidade de participar das decisões, de acessar conhecimentos, de se qualificar e de agregar renda.

Além desses aspectos, as organizações de economia solidária pressupõem que as relações humanas estabelecidas nesses contextos são relações de igualdade, de colaboração e preocupação com o outro, o que as difere em essência daquelas que normalmente ocorrem nas organizações estruturadas em competitividade. 
Sob esse viés, a percepção da força individual, manifestada por meio de comportamentos autoconfiantes, pressupõe o empoderamento psicológico, conceito que se aproxima da noção de autonomia, por estar relacionado "à capacidade de os indivíduos e grupos poderem decidir sobre as questões que lhes dizem respeito, escolher, enfim entre cursos de ação alternativos em múltiplas esferas - política, econômica, cultural, psicológica, entre outras" (HOROCHOVSKI; MEIRELLES, 2007, p. 486).

\section{Economia Solidária}

A economia solidária caracteriza-se como um dos vetores do desenvolvimento sustentável. Com o propósito de explicitar alguns conceitos, pressupostos e características que envolvem o conceito de economia solidária, são apresentados, a seguir, alguns conhecimentos já produzidos, no Brasil, acerca desse movimento.

O Atlas da Economia Solidária no Brasil - 2005 (BRASIL, 2006), apresenta o mapeamento nacional da economia solidária em 2.274 municípios, valor relativo a $41 \%$ do total dos municípios brasileiros. O relatório informa que 14.954 empreendimentos econômicos solidários foram objeto de visita para coleta de informações. São exemplos de empreendimentos econômicos solidários as organizações de finanças solidárias, empresas autogestionárias, cooperativismo popular, redes de empreendimentos, associações e clubes de troca. Além destes, integram ainda a relação de organizações partícipes da economia solidária outros atores como universidades, organizações não governamentais, organizações de natureza religiosa, movimento sindical, ligas e uniões, entre outras.

A Secretaria Nacional de Economia Solidária(SENAES) caracteriza essas organizações como um conjunto de atividades econômicas de produção, distribuição, consumo, poupança e crédito. Tais atividades são organizadas sob a forma de autogestão, ou seja, pela propriedade coletiva dos meios de produção de bens ou prestação de serviços, pela participação democrática nas decisões dos membros da organização ou empreendimento e pela distribuição equitativa dos resultados do trabalho (SENAES, 2004). Singer (2002) acrescenta, ainda nesse conjunto de características, a propriedade coletiva ou associada ao capital e o direito à liberdade individual.

No entender de Singer e Souza (2000), o modelo de economia solidária não se consagra a partir da exigência de solidariedade ou da solidariedade imposta. Antes disso, essa condição deve ser absorvida e vivenciada como um valor, uma norma pelas pessoas. De forma semelhante, Sawaia (1996) evidencia que os valores comunitários devem ser pensados e sentidos como necessidade e interiorizados como projeto individual para se transformarem em ação.

Veronese e Guareschi (2005) descrevem a economia solidária como um espaço laboral passível de constituir modos singularizados de trabalhar. Para esses autores, diversas formas de organização são representativas da economia solidá- 
ria, como por exemplo, cooperativas, associações, grupos informais etc. E, ainda que tais organizações sejam diferentes, o que lhes confere semelhança é o fato de que contêm (ou deveriam conter):

[...] um projeto de desenvolvimento destinado a promover as pessoas e coletividades sociais a sujeito dos meios, recursos e ferramentas de produzir e distribuir as riquezas, visando à suficiência em resposta às necessidades de todos e o desenvolvimento genuinamente sustentável (VERONESE; GUARESCHI, 2005, p. 60).

A economia solidária traz, intrinsecamente associada ao seu escopo, a vontade de transformar a sociedade contemporânea. Lisboa (2000) destaca que suas propostas não se restringem a alternativas de combate ao desemprego porque práticas-propositivas integram um movimento de resistência e de rebeldia à lógica capitalista e cartesiana. Faz parte de sua lógica um movimento social maior, antiutilitarista, que reivindica a "reintegração da atividade econômica nas relações sociais através da desmercantilização da terra, do trabalho e do dinheiro" (LISBOA, 2000, p. 67).

Essas organizações integram e associam trabalhadores que, preteridos do processo produtivo capitalista, tanto por fatores estruturais (concentração da propriedade privada) como conjunturais (desemprego). Isto porque tal proposta possibilita formas de inclusão no contexto produtivo que se torna mais democratizado, pois cria expectativas de justiça social em razão da participação nas iniciativas empreendedoras e no consumo de bem-estar social (SILVA, 2004).

Na essência dos propósitos da economia solidária há a intenção de transformação das relações econômicas, de maneira que passem a ser sustentadas por princípios e postulados determinados pela cooperação, solidariedade e inclusão, o que concorre para o estabelecimento de novas relações sociais de produção (SINGER, 1998).

Mance (1999, p. 179) contribui sobremaneira à compreensão da lógica existente no modelo de economia solidária:

O objetivo da colaboração solidária é garantir a todas as pessoas as melhores condições materiais, políticas, educativas e informacionais para o exercício de sua liberdade, promovendo assim o bem-viver de todos e de cada um. Não se trata apenas de uma proposta econômica para gerar empregos e distribuir renda. Mais do que isso, trata-se de uma compreensão filosófica da existência humana segundo a qual o exercício da liberdade privada só é legítimo quando deseja a liberdade pública, quando deseja que cada outro possa viver eticamente a sua singularidade dispondo das mediações que lhe sejam necessárias para realizar $\square$ nas melhores condições possíveis $\square$ a sua humanidade, 
exercendo a sua própria liberdade. Igualmente, sob esta mesma compreensão, a liberdade pública somente é exercida de modo ético quando promove a ética na realização da liberdade privada.

Singer (2008) complementa as razões que descrevem a importância da economia solidária na sociedade brasileira atual. Para o autor, esta iniciativa vem comprovar que a alienação no trabalho, própria da empresa capitalista, não é algo mandatório. Explica que nos modelos que apresentam heterogestão "a meritocracia justifica que o poder de decisão está concentrado no dono, o capitalista, depois em seus gerentes, enquanto a grande maioria é destituída de qualquer poder de decisão e mesmo de conhecimento sobre o conjunto" (SINGER, 2008, p. 289). Nestes termos, fica evidente que o fato de o capitalista e seus gerentes terem mais poder está associado à lógica de que o conquistaram porque têm maior capacidade do que os excluídos do mercado. De outro modo, nos empreendimentos de economia solidária, marcados pela autogestão, os trabalhadores decidem e são os proprietários de tudo o que é produzido, assim como dos eventuais prejuízos. Embora este fato promova certo estranhamento inicial, com o tempo os trabalhadores reconhecem ser essa uma experiência libertadora.

Não obstante os argumentos convincentes em profundidade e extensão, amplamente favoráveis a propostas dotadas de alta racionalidade social, a adoção de um modelo de desenvolvimento baseado na economia solidária é iniciativa tímida e com problemas de diversas ordens, consideradando-se as dimensões e os problemas característicos de um país continental, como o Brasil.

A timidez referida é resquício do neoliberalismo imposto aos países empobrecidos e dos problemas decorrentes do individualismo, da lógica predatória do mercado e da omissão do Estado e de suas responsabilidades sociais. Além disso, o movimento tem acompanhado as "recentes tendências dominantes no mundo capitalista contemporâneo quanto a programas de geração de renda em consonância com a reestruturação produtiva e desregulação no campo da proteção social" (BARBOSA, 2005, p. 187).

Por ser recente, essa iniciativa ainda não apresenta maturidade suficiente capaz de ensejar propostas no plano tecnológico. Em razão disso, seu potencial apresentará limitações, se não acontecer a elaboração de uma base cognitiva (inclusive tecnológica) que possibilite a sustentabilidade das iniciativas autogestionárias (DAGNINO, 2000).

A imaturidade presente na proposta de economia solidária revela ainda que há dificuldades a serem enfrentadas, quando se preconiza a passagem da condição de trabalhador a empreendedor de iniciativas autogeridas. Por exemplo, Singer (2008) refere que nas organizações capitalistas os trabalhadores não participam dos lucros, dos prejuízos ou das decisões. Deste modo, esperar que passem da absoluta irresponsabilidade e falta de conhecimento, próprios das empresas que fizeram parte de suas experiências, à condição de responsabilidade coletiva pode ser algo grandioso, porém problemático. A escassez de 
capital e dificuldades de acesso aos mercados, na visão do autor, tem forçado os trabalhadores de cooperativas a participarem da competição mercadológica. Contudo, tal situação é marcada pelo sacrifício de seus próprios membros que, em alguns casos, nem querem ser regulados.

A partir da ótica da sustentabilidade, do gerenciamento e dos fatores humanos imbricados no processo, a economia solidária pressupõe iniciativas democráticas de autogestão fortemente disseminadas e alardeadas nos modelos de gestão mais atuais. Nas organizações de economia solidária, essas iniciativas carregam em seu escopo a possibilidade de estabelecimento do processo de vinculação entre o sujeito, seu trabalho e a organização. Satisfação, envolvimento, comprometimento, suporte, reciprocidade e justiça organizacional encontram maior possibilidade de se concretizarem ou se estabelecerem em organizações solidárias do que em organizações competitivas. A maior responsabilização e participação do trabalhador nas decisões são razões que justificam essa afirmação. Isso é possível em razão de que as organizações de economia solidária proporcionam aos sujeitos que nelas trabalham a capacitação para a participação e para o próprio trabalho. É pertinente ainda considerar que, nas organizações de economia solidária autogeridas, a transparência na gestão e o empenho dos gestores para a consecução das metas e objetivos constituem fontes de eficiência consideráveis.

Quando oportunizadas vivências e experiências de dignidade, justiça e equidade, o trabalho amplia-se e é enriquecido para além da técnica e do método. Essa experiência integral, sob a ótica cognitiva ou emocional, possibilita a ascensão a níveis mais elevados de satisfação. O trabalho, antes fonte de sobrevivência, passa a comportar dimensões mais elevadas de autorrealização. Nesse contexto, a possibilidade de ver em ação trabalhadores-gestores fortemente comprometidos com o futuro da organização é muito maior que em organizações onde a participação é limitada e há o distanciamento oportunista entre o sujeito que trabalha, os meios de seu trabalho e aquilo que ele produz, o que pode ser traduzido em alienação e submissão.

Contraponto ao explicitado, a deficiência de capacitação formal para os cargos de gestão pode constituir um problema nesse modelo, pois embora tenham conhecimento tácito e explícito do processo produtivo, os trabalhadores gerentes carecem, na maioria das vezes, de experiências e conhecimento do mercado, para atender às exigências legais e de habilidade para conquistar parcerias, entre outros. Essas são importantes questões mercadológicas e macro-organizacionais que não podem/devem ser negligenciadas.

Além disso vale ainda comentar que a maioria das empresas de autogestão é constituída por pessoas sem grande patrimônio pessoal (recursos próprios podem ser destinados ao financiamento do capital de giro) e reduzido grau de instrução. Essas situações podem concorrer para as experiências pouco exitosas ou de sucesso duvidoso. 


\section{Consumo Solidário}

Definições, características e pressupostos buscam desvelar especificidades da economia solidária, permitindo considerar a criticidade que deve envolver discussões sobre o consumo. Tudo o que é consumido pela população é produto de um processo produtivo perpassado por um determinado conceito de sociedade.

Em associação à crítica enunciada, o modelo de economia solidária pressupõe o consumo solidário decorrente da seleção do que consumir, sustentada pela consideração para além do próprio bem-viver pessoal, e igualmente determinada pelo bem-viver coletivo (MANCE, 1999). Ainda, é considerado solidário o consumo que privilegia o coletivo antes do individual; que é responsável, na medida em que o que é consumido está de acordo com o necessário, sem desperdício. Por isso, é convicto, rejeita e opõe-se ao supérfluo, mesmo diante dos apelos infindáveis da mídia. Tais entendimentos respaldam-se na Declaração Mundial dos Direitos Humanos que assevera a alimentação como uma necessidade vital, portanto, um direito fundamental de cada pessoa de acordo com as singularidades de cada um. Assim, dois pressupostos básicos à vida em coletivo perpassam esses enunciados: a justiça e a equidade.

As práticas de consumo solidário são direcionadas pela preferência por produtos e serviços que não exploram trabalhadores e não agridem o meio ambiente. Quando concebidas como empreendimentos, se produzirem excedentes, estes serão reinvestidos coletivamente, de maneira a criar novos postos de trabalho, ampliar a cadeia produtiva, aumentar o consumo produtivo de materiais de manutenção, insumos, entre outros. O resultado desse processo é a realimentação do próprio sistema.

\section{Algumas possibilidades de contribuição da Psicologia}

De modo a ampliar a problematização dos conceitos já referidos, é pertinente considerar que o neoliberalismo estendeu sobre a sociedade "seus tentáculos sub-repticiamente sobre qualquer sinal de reação, antes que esta percebesse sua verdadeira face e se reconhecesse como tal" (SILVA, 2004, p. 15). Quando se avalia o consumo e a produção, constata-se que o mercado neoliberal promoveu o alijamento de milhões de pessoas. Como consequência, as forças do capital, concebidas pelo mercado, reproduziram o modelo de dominação em prejuízo do aspecto social/comunitário (SILVA, 2004).

As contribuições que a Psicologia pode dar à temática proposta, quando se reflete a respeito do neoliberalismo e suas consequências sobre uma significativa parcela da sociedade - os excluídos - estão assentadas na problematização das práticas de consumo, das significativas diferenças de consumo entre classes sociais, de novos modelos de economia e de organizações de trabalho sob a ótica das relações que neles se processam. Assim sendo, urgem intervenções, sob a perspectiva da ciência psicológica, no âmbito das técnicas, das estratégias e das políticas no sentido de se promover a autonomia dos sujeitos dispostos a protagonizarem as novas propostas de economia solidária. 
Ter recursos humanos e apoio financeiro é imprescindível, mas isso por si só não é suficiente: há que se suster o novo empreendedor tecnicamente de modo a se concretizar a efetiva geração de trabalho e renda. Oportunizar aos sujeitos acesso a conhecimentos que permeiam uma perspectiva transformadora e que os tornem competitivos em relação ao mercado capitalista pode representar uma alternativa ao insucesso das políticas públicas. Numa instância ampliada enseja certa justiça social e exercício pleno da cidadania.

Em sendo o papel social da Psicologia a aproximação/minimização das diferenças, esta ciência tem responsabilidade assumida perante a sociedade na promoção de espaços e criação de novas institucionalidades. Deste modo, empoderar a sociedade representa uma maior participação em debates, negociações, deliberações e acesso a informações relativas às políticas públicas que de algum modo alcancem as pessoas, permitindo-lhes a participação, ainda que de forma indireta, por meio do alargamento dos fóruns representativos (HOROCHOVSKI; MEIRELLES, 2007).

Promover a efetiva autonomia, o enriquecimento de aspectos essenciais à vivência e convivência entre as pessoas, promover a harmonia entre indivíduos e ambiente com vistas à qualidade de vida, ao bem-estar e à criticidade da realidade social são alguns dos aspectos norteadores do fazer dos psicólogos na interface com a economia solidária, com a emancipação e autonomia dos sujeitos, com o compromisso ético do consumo solidário e com a sustentabilidade ambiental.

Além disso, o empoderamento dos sujeitos protagonistas das novas propostas de economia solidária é perpassado pelos pressupostos da reciprocidade e dos vínculos sociais e permeados pela defesa da justiça social e do exercício da plena cidadania. Todos esses aspectos, transarticulados com e por conceitos e teorias psicológicas, merecem constantes estudos e investimentos na produção de novos conhecimentos que possam propor alternativas renovadas de inclusão social.

\section{Considerações Finais}

Sistematizar brevemente conhecimentos e analisar, sob a ótica da Psicologia, o consumo, o comportamento de consumir, o consumo solidário e a proposta renovadora das relações econômicas estabelecidas na sociedade representada pelo movimento da economia solidária constituíram os objetivos desse artigo. Em nenhum momento houve a pretensão de esgotar o assunto ou ser conclusivo, antes, sim, de dar visibilidade a aspectos importantes de forma a possibilitar uma reflexão a respeito desses conceitos importantes e necessários à sociedade, mas pouco reconhecidos. Neste viés, é reconhecida a importância de novos estudos e pesquisas que ampliem a discussão, problematização e reflexões por parte da academia e da sociedade em geral a respeito do consumo consciente, da economia solidária e da influência da mídia sobre os hábitos de consumo.

Após o anúncio da inesgotabilidade dos temas até aqui problematizados e do reconhecimento da necessidade da ampliação do conhecimento sobre os fenômenos tratados ao longo do texto destaca-se que timidamente começam a 
vigorar, em governos estaduais e municipais, políticas públicas direcionadas a minimizar as ameaças e potencializar as oportunidades dos empreendimentos solidários. Contudo, continuam sendo urgentes e necessárias. Compromisso com a formação e capacitação de trabalhadores-gestores, aporte de crédito, incentivo ao comércio solidário e trabalho em rede são possibilidades já discutidas por formuladores dessas políticas.

Todavia, novas forças produtivas em substituição ao modelo capitalista predominante exigem ações gerenciais, políticas, econômicas e sociais que, permanentemente avaliadas, poderão consolidar outros arranjos sociais e laborais. Ainda que tornada real essa possibilidade, os empreendimentos solidários não sobrepujarão os empreendimentos capitalistas, pois, conforme destaca Singer (1998), a autogestão não é uma estratégia inferior à gestão capitalista no desenvolvimento das forças produtivas e cabe à economia solidária dar prova irrefutável disto.

A fome em escalada mundial, a diminuição acelerada dos mananciais de água potável, os impactos ambientais decorrentes da industrialização acelerada, o consumo desmedido e nada crítico, exigem da sociedade um novo modelo de desenvolvimento. Melo Neto e Fróes (2002) propõem que esse modelo deve privilegiar o indivíduo em sociedade, seu valor e sua capacidade para inovar e empreender, mas ser centrado nas pessoas e nos grupos sociais. Deve vê-los como os únicos sujeitos legítimos do desenvolvimento; basear-se em valores como cooperação, partilha, reciprocidade, complementaridade e solidariedade; seus princípios ativos, as qualidades humanas e os recursos naturais disponíveis. A proposta dos autores referenda um modelo de desenvolvimento comunitário cujo foco recai na comunidade, em sua capacitação, empoderamento, mobilização e conscientização. Deve ser sustentado, porque seu objetivo é dar autonomia às pessoas, grupos e comunidade para agirem em seu próprio benefício, tornando-os independentes e autossuficientes. O modelo também há de ser integrado por se desenvolver sob a forma de redes de cooperação entre diversos agentes - governo local, empresas e organizações sociais.

Utopia? Talvez. Todavia, não é possível deixar de considerar que as utopias são, em última instância, críticas à realidade. E, ainda que não existam respostas prontas ou acabadas a questões que projetam ou garantam as expectativas de futuro, um argumento parece certo: não é mais possível referendar a vida em sociedade no consumo em grande escala, em comportamentos individualistas, em expropriação da lógica das comunidades, em exploração ou domínio de alguns sistemas sobre outros. Cada ser desse maltratado planeta necessita, com urgência, repensar "a parte que lhe cabe neste latifúndio". 


\section{REFERÊNCIAS}

BARBOSA, R. N. C. A economia solidária como política pública: uma tendência de geração de renda e ressignificação do trabalho no Brasil. São Paulo: Pontifícia Universidade Católica de São Paulo, 2005.

BAUDRILLARD, J. A sociedade de consumo . Lisboa: Edições 70, 1995.

BAUDRILLARD, J. O Sistema dos objetos. São Paulo: Perspectiva, 1997.

BOONE, L. E.; KURTZ, D. L. Marketing contemporâneo. 8. ed. Rio de Janeiro: Livros Técnicos e Científicos, 2001.

BRASIL. Ministério do Trabalho e Emprego. Atlas da Economia Solidária no Brasil - 2005. Brasília: SENAES, 2006.

BRASIL. Ministério do Trabalho e Emprego. Sistema nacional de informações em economia solidária. Termo de referência para o Mapeamento da Economia Solidária. Brasília: SENAES, 2004. Disponível em $<$ http://portal.mte.gov.br/ portal-mte/>. Acesso em: 20 dez. 2006.

CHAUVEL, M. A. A satisfação do consumidor no pensamento de marketing: revisão de literatura. In: Encontro Nacional da ANPAD, 23., 1999. Foz do Iguaçú, Paraná. Anais... Foz do Iguaçú: ENANPAD, 1999. 1 CD-ROM.

CORRALES, O. Publicidade, consumo y gobierno de la subjetividad: comunicación y medios. Rev. Universidade do Chile, Chile, v.16, n. 15, 2005. p. 209-219.

DAGNINO, R. Em direção a uma Estratégia para a redução da pobreza: a Economia Solidária e a Adequação Sócio-técnica. Organização dos Estados Iberoamericanos -OEI, 2000. Disponível em: <http://www.oei.es/salactsi/ rdagnino5.htm>. Acesso em: 21 ago. 2011.

GADE, C. Psicologia do consumidor e da propaganda. São Paulo: Pedagógica e Universitária, 1998.

HOROCHOVSKI, R. R; MEIRELLES, G. Problematizando o conceito de empoderamento. In: SEMINÁRIO NACIONAL MOVIMENTOS SOCIAIS, PARTICIPAÇÃO E DEMOCRACIA, 2., 2007, Florianópolis. Anais... Florianópolis: UFSC, 2007. p. 485-506.

KARSAKLIAN, E. Comportamento do consumidor. São Paulo: Atlas, 2000. 
KINCHELOE, J. Mc Donald's, poder e criança: Ronald Mc Donald faz tudo por você. In: SILVA; AZEVEDO; SANTOS (Org.). Identidade social e a construção do conhecimento. Porto Alegre: Secretaria Municipal de Educação, 1997. p. 6998.

LISBOA, A. M. Os desafios da Economia Popular Solidária. Cadernos do CEAS. Salvador, n. 189, p.51-67, 2000.

MANCE, E. A. A revolução das redes: a colaboração solidária como uma alternativa pós-capitalista à globalização atual. Petrópolis: Vozes, 1999.

MELO NETO, F. P.; FROES, C. Empreendedorismo social: a transição para a sociedade sustentável. Rio de Janeiro: Qualimark, 2002.

MOSER, G. Examinando a congruência pessoa-ambiente: o principal desafio para a Psicologia Ambiental. Estud. Psicol. (Natal), Natal, v. 8, n. 2, p. 331-333, ago. 2003. .

OLIVEIRA, A. L. O processo de empoderamento de mulheres trabalhadoras em empreendimentos de economia solidária. Dissertação (Mestrado)-Universidade Federal de Santa Catarina, Florianópolis, 2004.

PADUA, J. A. Produção, consumo e sustentabilidade: o Brasil e o contexto planetário. Cadernos de Debate, 2000. Disponível em: <http://cursa.ihmc. us/rid=1 GM6G3K7D-27Y228J-47B/PRODUCAO\%20CONSUMO \%20 SUSTENTABILIDADE.doc> Acesso em: 21 ago. 2011.

PINHEIRO, J. Q. Psicologia ambiental: a busca de um ambiente melhor. Estud. Psicol. (Natal), Natal, v. 2, n. 2, p. 377-398, jul./dez. 1997.

SANTOS, E. A. A. O consumismo como um novo iluminismo: a panacéia do consumo na contemporaneidade. Dissertação (Mestrado)-Universidade Federal de Santa Catarina, Florianópolis, 2006.

SAWAIA, B. B. Comunidade: a apropriação científica de um conceito tão antigo quanto a humanidade. In: CAMPOS, R. H. F. (Org.). Psicologia Social Comunitária: da solidariedade à autonomia. Petrópolis: Vozes, 1996. p. 35-53.

SILVA, J. R. CEBs: um atalho para a inclusão social na pós-modernidade. In: Memória e Caminhada. Brasília/UCB, n. 7, dez. 2004.

SINGER, P. Uma utopia militante: repensando o socialismo. Petrópolis: Vozes, 1998.

SINGER, P. Introdução à Economia Solidária. São Paulo: Perseu Abramo, 2002. 
SINGER, P. Economia solidária. Estud. Av., São Paulo, v. 22, n. 62, p. 289-314, jan./abr. 2008.

SINGER, P.; SOUZA, A. R. (Org.) A economia solidária no Brasil: a autogestão como resposta ao desemprego. São Paulo: Contexto, 2000.

STEINBERG, S. Kindercultura: a construção da infância pelas grandes corporações. In: SILVA; AZEVEDO; SANTOS (Org.). Identidade social e a construção do conhecimento. Porto Alegre: Secretaria Municipal de Educação, 1997. p. 99-145.

VERONESE, M. V.; GUARESCHI, P. Possibilidades solidárias e emancipatórias do trabalho: campo fértil para a prática da Psicologia social crítica. Psicol. Soc., Porto Alegre, v. 17, n. 2, p. 58-69, maio/ago. 2005.

ZANELLI, J. C. Trabalhadores com manifestações de stress: teorias e procedimentos utilizados em centros de pesquisas e intervenções. Relatório Final (Pós-Doutorado Sênior)-Pontifícia Universidade Católica de Campinas, São Paulo, 2007.

Recebido em: 13 de fevereiro de 2010 Aceito em: 14 de setembro de 2011 